\title{
TECTONOPHYSICAL CRITERIA FOR FORECASTING THE LOCATIONS OF QUARTZ CRYSTAL DEPOSITS (CASE OF SUBPOLAR URAL)
}

\author{
L.A. Sim \\ O.Yu. Schmidt Institute of Physics of the Earth of RAS, Moscow, Russia
}

\begin{abstract}
Spatial reconstruction of tectonic stresses within the Subpolar Ural quartz crystal-containing province was conducted by the kinematic method [Gushchenko, 1973, 1979] based on the main indicators of tectonic stresses on slickensides. Local stress states (LSS) and general stress fields for large blocks were reconstructed by the method described in [Sim, Marinin, 2015]. In the blocks with numerous deposits of quartz crystal (Pelingichey and Omega-Shor blocks), the general stress fields is characterized by a stress state close to uniaxial tension, i.e. the Lode-Nadai coefficient $\mu=-1$. In these blocks, thick quartz veins are perpendicular to the tension axis of the general stress field. In the block without quartz crystal (West Saled), the general stress field is characterized by a triaxial stress state or pure shear state $(-1<\mu \sigma<+1)$. The LSS of the quartz crystal deposits show the following: the stress state of $\mu=-1$ is typical of quartz veins without quartz crystal nests, and a special kind of stress state is reconstructed in the nests with piezo raw material. It is named a variation of the type of stress state (VTSS), which means that within one tectonic stage, the type of stress state changes approximately as follows: $\mu \sigma=+1(40 \%), \mu \sigma=-1(40 \%)$, and $-1<\mu \sigma<+1$. It means that in the piezo raw mineral deposits, pulsating tectonic stresses provided for a fluid flow of hydrothermal solutions at the intersection of ore-bearing and ore-controling faults when tension $(\mu=-1)$ was replaced with compression $(\mu=+1)$, while the orientations of compression and tension axes remained unchanged. Apparently, such a regime was caused by alternating activation of the above-mentioned faults. The tectonic stress reconstructions were performed for 33 mineral deposits and occurrences of quartz crystal. VTSS was determined in 32 deposits; one mineral occurrence is characterized by uniaxial tension. Therefore, we propose using VTSS (variation of the type of stress state) as a criterion for predicting the locations of quartz crystal deposits.
\end{abstract}

KEYWORDS: Subpolar Ural; tectonic stress; variation of the type of stress state (VTSS); quartz vein; quartz crystal

FUNDING: The studies were supported by the Russian Foundation for Basic Research (Project No. 17-05-01193a) and carried out according to the state task of the Institute of Physics of the Earth of RAS. 


\title{
ТЕКТОНОФИЗИЧЕСКИЕ КРИТЕРИИ ПРОГНОЗА МЕСТ ЛОКАЛИЗАЦИИ ГОРНОГО ХРУСТАЛЯ (НА ПРИМЕРЕ ПРИПОЛЯРНОГО УРАЛА)
}

\author{
Л.А. Сим
}

Институт физики Земли им. О.Ю. Шмидта РАН, Москва, Россия

АНнотАЦИЯ. Площадная реконструкция тектонических напряжений кинематическим методом [Gushchenko, $1973,1979]$ в пределах Приполярно-Уральской хрусталеносной провинции позволила восстановить локальные тектонические напряжения (стресс-состояния - ЛСС) и общие поля напряжений для крупных блоков по методике [Sim, Marinin, 2015]. Общее поле напряжений для блоков, насыщенных месторождениями и проявлениями горного хрусталя, характеризуется видом напряженного состояния, близким к одноосному растяжению, т.е. коэффициент Лоде - Надаи $\mu \sigma=-1$ (Пелингичейский, Омега-Шорский блоки). В этих блоках мощные кварцевые жилы ориентированы перпендикулярно оси растяжения общего поля напряжений. В блоке без горного хрусталя (Западные Саледы) общее поле напряжений характеризуется трехосным напряженным состоянием $(-1<\mu \sigma<+1)$. ЛСС на месторождениях показывают следующее: в кварцевых жилах без гнезд горного хрусталя вид напряженного состояния $\mu \sigma=-1$, а в стенках гнезд с пьезосырьем восстанавливается особый вид напряженного состояния, названный нами вариацией вида напряженного состояния (BBHC), т.е. за один тектонический этап вид напряженного состояния изменяется примерно следующим образом: $\mu \sigma=+1(40 \%)$, $\mu \sigma=-1(40 \%)$ и $-1<\mu \sigma<+1(20 \%)$. Это означает, что для подтока гидротермальных растворов на местах пересечения рудоподводящих и рудоконтролирующих разломов на месторождениях пьезосырья был пульсирующий режим тектонических напряжений, когда обстановка растяжения $(\mu \sigma=-1)$ менялась на обстановку сжатия $(\mu \sigma=+1)$ при неизменной ориентировке осей сжатия и растяжения. По-видимому, такой режим вызывался попеременной активизацией двух типов вышеназванных разломов. Из 33 обследованных месторождений и проявлений горного хрусталя на 32 была установлена ВBНC, на одном проявлении - обстановка одноосного растяжения, что позволило предложить вариацию вида напряженного состояния как критерий для прогноза мест локализации горного хрусталя.

КЛЮЧЕВЫЕ СЛОВА: Приполярный Урал; тектоническое напряжение; вариация вида напряженного состояния; разлом; кварцевая жила; горный хрусталь

ФИНАНСИРОВАНИЕ: Исследования выполнены при поддержке РФФИ в рамках научного проекта №17-05-01193а и по госЗаданию ИФЗ РАН.

\section{1. ВВЕДЕНИЕ}

На территории Приполярного Урала комплексом тектонофизических методов произведена реконструкция тектонических напряжений.

Приполярно-Уральская провинция жильного кварца и горного хрусталя находится в пределах Центрально-Уральского поднятия. Ее протяженность с юга на север составляет около 150 км, при этом она занимает как западный, так и восточный склон Приполярного Урала. В тектонике провинции значительную роль играет складчато-надвиговая структура Ляпинского антиклинория, известная также как Кожимское поперечное поднятие, которое сложено в разной степени дислоцированными и метаморфизованными осадочными, вулканогенными и интрузивными телами. Западнее Ляпинского антиклинория развиты палеозойские отложения.

В центральной части региона выделяется жесткий блок, сложенный наиболее древним раннепротерозойским высокометаморфизованным няртинским или николайшорским гнейсомигматитовым комплексом. Этот комплекс окружен широко распространенными в регионе отложениями рифея и венда, среди которых выделяются маньхобеинская, щекурьинская, пуйвинская, хобеинская, мороинская, саблегорская, лаптопайская свиты. Эти свиты представлены серицит-альбит-кварцевыми, серицит-хлорит-кварцевыми, хлорит-альбиткварцевыми сланцами, известковистыми сланцами с прослоями и линзами кварцитов, кварцевых конгломератов, мраморов, известняков, кислыми и основными вулканитами и их туфами [Bukanov et al., 2012; Karyakin, Smirnova, 1967].

На западе от Центрально-Уральского поднятия расположены залегающие несогласно на более древних породах палеозойские отложения, разрез которых на исследуемой территории начинается со среднеордовикских отложений.

На рис. 1 показаны три крупных блока, выделенных с помощью расчета плотности месторождений и проявлений горного хрусталя Приполярно-Уральской хрусталеносной провинции: Пелингичейский, захватывающий верховья рек Балбанью и Пелингичей (месторождения Пелингичей-1, 2, Гранитное и др.); ОмегаШорский - в верховьях рек Вангыр, Большой Паток и Щекурья (месторождения Додо, Омега-Шор, Пуйва и др.), а также на западном склоне Приполярного Урала Западно-Саледский блок без крупных месторождений горного хрусталя. 


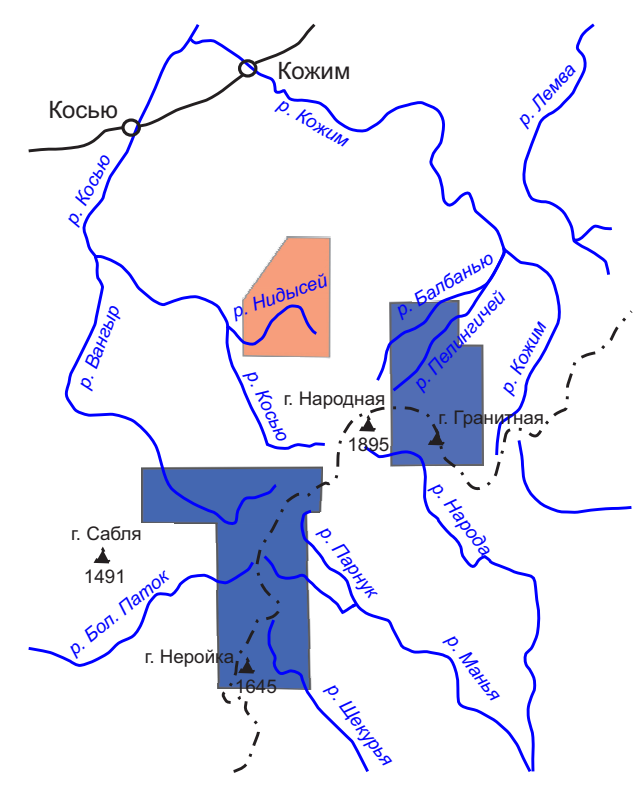

Рис. 1. Приполярный Урал. Район работ. Синим цветом выделены хрусталеносные Пелингичейский (на северо-востоке) и ОмегаШорский (на юге) блоки; оранжевым цветом выделен ЗападноСаледский безрудный блок.

Fig. 1. Subpolar Urals. Study area. Blue - Pelingichey (north-east) and Omega-Shor (south) blocks with quartz crystal occurrences; orange - West Saled block without quartz crystal.

В пределах Пелингичейского и Омега-Шорского блоков сконцентрировано большинство кварцево-жильных и хрусталеносных месторождений. Наиболее крупные месторождения Додо и Пуйва (восточный склон) локализованы в сланцах пуйвинской свиты среднего рифея, а месторождение Желанное (западный склон) приурочено к кварцитопесчаникам тельпосской свиты нижнего ордовика.

\section{2. МЕТОДИКА ИССЛЕДОВАНИЙ}

Реконструкция тектонических напряжений производилась кинематическим методом [Gushchenko, 1973, 1979]. Похожий метод был разработан Ж. Анжелье [Angelier, 1994]. Основным индикатором тектонических напряжений являются борозды, ступени и штрихи на зеркалах скольжения - векторы перемещений. То, что проекция вектора перемещения на плоскости действия максимальных касательных напряжений внешнего поля соответствует вектору перемещения на произвольно ориентированной к внешнему полю напряжений плоскости, отметил М. Ботт [Bott, 1959]. Это свойство использовано в кинематическом методе для нахождения ориентации осей главных нормальных напряжений по бороздам скольжения, измеренным в некотором объеме горных пород. Основным условием при этом является один масштабный уровень плоскостей, по которым произошли смещения под воздействием внешнего поля напряжений. С использованием кинематического метода в точках наблюдения восстанавливались ЛСС для отдельных объемов горных пород. Для этого на единую стереограмму были нанесены все векторы перемещений, измеренные в ограниченном объеме и был произведен их анализ согласно кинематическому методу, который позволяет восстанавливать ЛСС в точке наблюдения.

Указанный метод в графическом варианте дает возможность определять на качественном уровне коэффициент Лоде - Надаи $\mu \sigma$. В случае, когда векторы перемещений (борозды скольжения) совпадают с дугами больших кругов, расходящихся от оси найденного по этим векторам растяжения $\sigma_{1}$, коэффициент Лоде - Надаи $\mu \sigma=-1$, т.е. определено состояние одноосного растяжения. В случае, когда векторы перемещений совпадают с дугами больших кругов, расходящихся от оси сжатия $\sigma_{3}$, объем деформируется в обстановке одноосного сжатия, т.е. $\mu \sigma=+1$. Если векторы перемещений попадают в створ острого угла между дугами больших кругов, расходящихся от осей $\sigma_{1}$ и $\sigma_{3}$, то объем деформируется в обстановке трехосного напряженного состояния или обстановке чистого сдвига, т.е. $|\mu \sigma| \neq 1$. Единичные векторы перемещений, не совпадающие с дугами больших кругов, расходящихся от оси растяжения (или сжатия), попадающие в створ острого угла на стереограммах с одноосным видом напряженного состояния, позволяют определить ориентацию всех трех осей главных нормальных напряжений, как это показано на рис. 2, а-в [Sim et al., 2005].

В работе [Lacombe, 2012] при обсуждении сравнения палеонапряжений с современными отмечается важность ранжирования напряжений как по времени их проявления, так и по масштабу усреднения. Эта постановка важна для разработки формализованного метода усреднения локальных стресс-состояний по некоторой площади.

Такой метод нахождения общего поля напряжений по данным о ЛСС был предложен автором в 1982 г., обоснование изложено в работе [Sim, Marinin, 2015]. В принципе, обоснованном в этом методе, в конусе растяжения не должно быть осей сжатия ЛСС, а в конусе сжатия, соответственно, осей растяжения ЛСС. Оба конуса имеют угол при вершине $90^{\circ}$, оси этих конусов являются осями общего, внешнего поля напряжений для некоторого блока горных пород. Это положение основано на данных математического и физического моделирования, которые показали следующее: если к некоторому объему горных пород приложены извне определенно ориентированные оси сжатия и растяжения, а в объеме есть разрывы, более мелкие, чем этот объем, то на концах разрыва возникают возмущения ориентировок осей сжатия и растяжения внешнего поля напряжений. Возмущения связаны с подвижкой по разломам. Различие ориентировок осей сжатия и растяжения возмущенного поля не превышает $45^{\circ}$ по сравнению с ориентировками главных нормальных напряжений внешнего поля [Osokina, 1987], соответственно все возмущенные локальные поля можно описать конусами сжатия и растяжения. Похожий подход нахождения «региональной» оси растяжения соблюдается в работе Т.Л. Стефенса с соавторами [Stephens et al., 2018], в которой определяются оси растяжения для даек и жил и подчеркивается, что в областях, где 

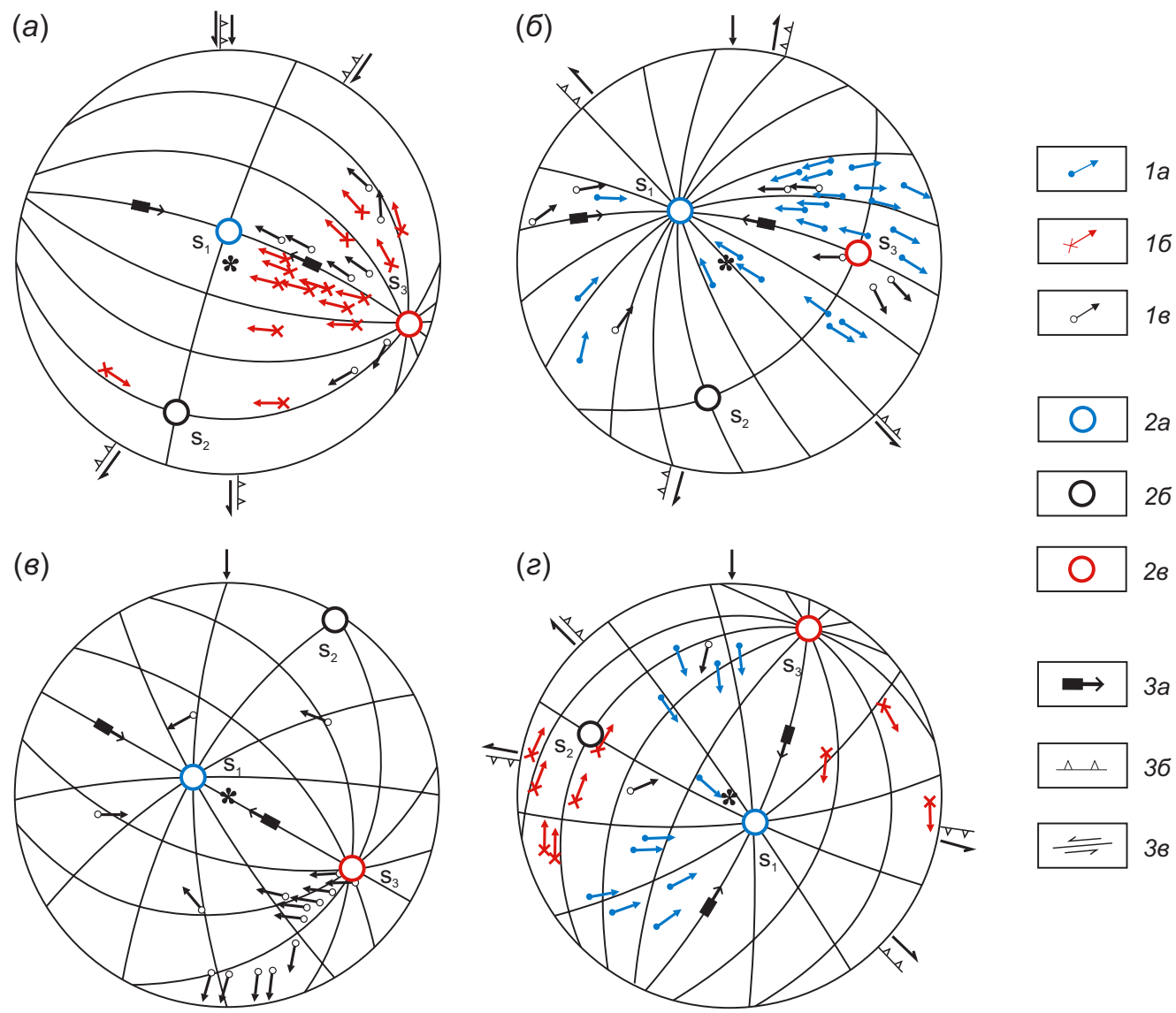

Рис. 2. Стереограммы определения ЛСС. Пелингичейский блок. Сетка Вульфа, верхняя полусфера.

1 - векторы перемещений на зеркалах скольжения, совпадающие с дугами больших кругов, расходящихся: $a$ - от оси растяжения (одноосное растяжение), б - от оси сжатия (одноосное сжатие), в - находящиеся в створе острого угла между дугами больших кругов, расходящихся от осей сжатия и растяжения (трехосное напряженное состояние); 2 - оси главных нормальных напряжений: $a$ - растяжения, 6 - промежуточная, 8 - сжатия; 3 - плоскости действия максимальных касательных напряжений: $a$ - полюс, б, в - кинематические типы (простирания плоскостей, вынесены за пределы круга): б - взбросы, $в$ - сдвиги. $(a)-(2)$ - различные типы напряженного состояния: $(a)$ - одноосного сжатия, (б) - одноосного растяжения, $(8)$ - чистого сдвига (трехосного напряженного состояния), (2) - вариация вида напряженного состояния (ВBНC).

Fig. 2. Stereograms for determining local stress states (LSS). Pelingichey block. Wulff net, upper hemisphere.

1 - shear vectors on slickensides, which coincide with the arcs of large circles diverging from tension axis (uniaxial tension) ( $a$ ) and compression axis (uniaxial compression) (б), and located at the sharp angle between the arcs of large circles diverging from the axes of compression and tension (triaxial stress state) $(\theta) ; 2$ - axes of the main normal stresses: $a$ - tension, $\sigma$ - intermediate, $\theta$ - compression; 3 - planes of maximum tangential stresses: $a$ - pole, $\sigma, \varepsilon-$ kinematic types (strike of planes, outside the circle): $\sigma$ - reverse faults, в - strike-slip faults. $(a)-(2)$ - various types of stress state: $(a)$ - uniaxial compression, (б) - uniaxial tension, $(b)$ - pure shear (triaxial stress state), (2) - variation of the type of stress state, VTSS).

отсутствуют структуры хрупкой деформации, дайки, силлы и жилы служат индикаторами ориентировок осей растяжения. А. Ямаджи и К. Сато также используют ориентацию даек и жил, которые выполняют трещины растяжения с использованием специального математического аппарата [Yamaji, Sato, 2011].

\section{3. РЕЗУЛЬТАТЫ ИССЛЕДОВАНИЙ И ИХ ОБСУЖДЕНИЕ}

На множестве объемов горных пород по площади исследований были восстановлены обстановки одноосного растяжения в зальбандах кварцевых жил при доминировании обстановок трехосного напряженного состояния по площади вне месторождений пьезосырья. Одновременно на месторождениях пьезосырья был установлен особый вид напряженного состояния, когда векторы перемещений от $30 \%$ и более расходятся от оси растяжения и примерно столько же - от оси сжатия. При этом векторы перемещений, находящиеся в створе острого угла и измеренные в одном и том же объеме горных пород, позволяют определять ориентацию осей сжатия и растяжения ЛСС, как показано на рис. 2, 2.

Согласно методике Ж. Анжелье [Angelier, 1994] по такой стереограмме было бы определено два ЛСС: 1 близкое к одноосному растяжению, 2 - близкое к одноосному сжатию; при этом в работах, в которых используется метод Ж. Анжелье, отмечается тенденция согласования двух таких ЛСС с крупными тектоническими событиями в большом регионе. О.И. Гущенко 
рассчитал все варианты ориентировок векторов перемещений на всем возможном комплексе плоскостей в едином однородноосно (постоянная ориентация осей главных нормальных напряжений) нагруженном объеме горных пород при меняющихся значениях коэффициента Лоде - Надаи: $-1 \leq \mu \sigma \leq+1$ [Gushchenko, 1979].

Согласно этим расчетам при меняющемся значении коэффициента Лоде - Надаи, но неизменной ориентации осей сжатия и растяжения могут сосуществовать векторы перемещений, образовавшиеся при разных величинах $\mu \sigma$. Уверенность в том, что ВВНС - свойство напряженного состояния одного тектонического этапа, а не двух разных, связана с тем, что оно картируется только в определенных точках наблюдения, а именно - вблизи гнезд горного хрусталя, как это будет показано ниже.
Месторождение Желанное является крупнейшим в России по запасам прозрачного жильного кварца и горного хрусталя [Gerasimov, Krivoshein, 2013]. На рис. 3 слева представлен план, справа - поперечный профиль этого месторождения, на котором синим пунктиром ограничена кварцевая жила. В верхней части карьера в точке 1 на стенке выбранного гнезда горного хрусталя было восстановлено ЛСС с вариацией вида напряженного состояния (левая стереограмма). Во вмещающих горных породах в стенке штольни 2 в точке 2 (рис. 3) в тех же кварцитопесчаниках восстановлены близкие к т.н. 1 ориентировки осей главных нормальных напряжений ЛСС (правая стереограмма). Но векторы перемещений относительно дуг больших кругов показывают, что объем горных пород здесь деформируется в обстановке с $|\mu \sigma| \neq 1$, близкой к трехосному
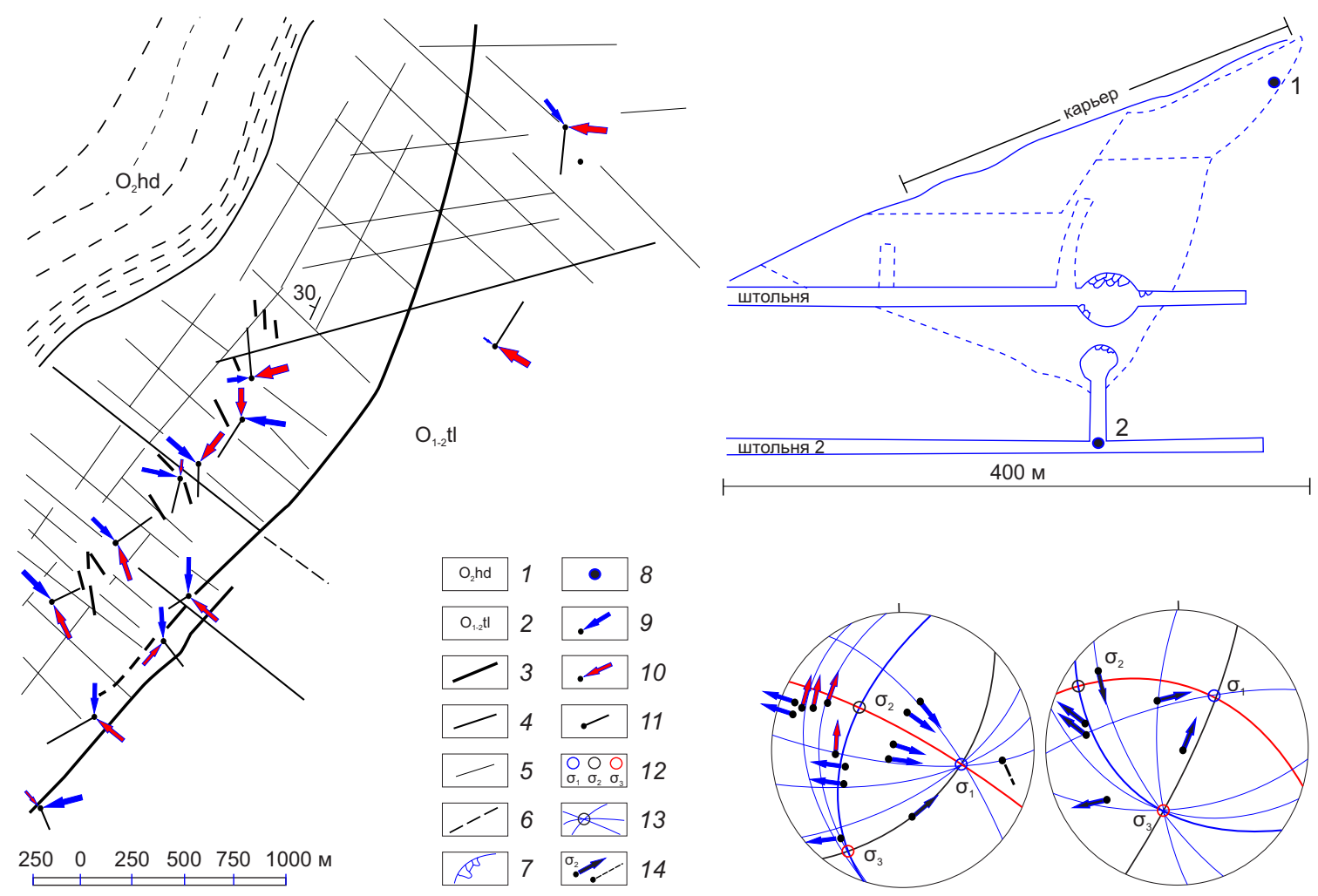

Рис. 3. Реконструкция тектонических напряжений на месторождении Желанное.

1 - отложения среднеордовикской (хыдейской свиты); 2 - нижне- и среднеордовикские отложения (тельпосская свита); 3-5 рудоподводящий (3), рудоконтролирующий (4) и прочие (5) разломы; 6 - горизонты хыдейской свиты; 7 - гнездо горного хрусталя; 8 - точки замеров зеркал скольжения и мелких структурных форм (на профиле); 9-11 - векторы перемещений, совпадающие с дугами больших кругов, расходящихся: 9 - от оси растяжения, 10 - от оси сжатия, 11 - с неопределенным знаком смещения; 12 - оси главных нормальных напряжений восстановленного локального поля напряжений или ЛСС: $\sigma_{1}$ - растяжения, $\sigma_{2}$ - промежуточная, $\sigma_{3}$ - сжатия; 13 - дуги больших кругов, расходящиеся от осей сжатия и растяжения; 14 - векторы перемещений, расположенные в створе острого угла между дугами больших кругов, расходящихся от осей $\sigma_{1}$ и $\sigma_{3}$ или противоречащие найденным осям (пунктирная линия) ЛСС. Сетка Вульфа, верхняя полусфера. Объяснения в тексте.

Fig. 3. Reconstruction of tectonic stresses. Zhelannoe deposit.

1 - Middle Ordovician deposits (Hydey suite); 2 - Lower and Middle Ordovician deposits (Telposs suite); 3-5 - ore-bearing (3), ore-controlling (4) and other (5) faults; 6 - layers of the Hydey suite; 7 - quartz crystal nest; 8 - measuring points on slickensides and small structural forms (on profile); 9-11 - shear vectors coinciding with the arcs of large circles diverging from: 9 - tension axis, 10 - compression axis, 11 - uncertain shear sign; 12 - axes of the main normal stresses of the reconstructed local stress field or LSS: $\sigma_{1}$ - tension, $\sigma_{2}$ - intermediate, $\sigma_{3}$ - compression; 13 - arcs of large circles diverging from the axes of compression and tension; 14 - shear vectors located at the sharp angle between the arcs of large circles diverging from the $\sigma_{1}$ and $\sigma_{3}$ axes or contradicting the axes (dashed line) of LSS. Wulf net, upper hemisphere. Explanation is in the text. 
напряженному состоянию (достаточно типичный вид напряженного состояния для объемов безрудных горных пород).

Ситуация напряженного состояния, близкая к восстановленному ЛСС в т.н. 1, была восстановлена на 32 месторождениях и проявлениях горного хрусталя из 33 исследованных. Это позволило назвать такой вид изменения коэффициента Лоде - Надаи $\mu \sigma$ в пределах одного объема горных пород ВВНС и предложить его как тектонофизический критерий мест концентрации пьезосырья. Такие специфические обстановки приурочены к участкам пересечения рудоподводящих и рудоконтролирующих разломов и, по-видимому, связаны с попеременной кратковременной активизацией рудоконтролирующих и рудоподводящих разломов, т.е. за один тектонический этап вид напряженного состояния изменяется примерно следующим образом: $\mu \sigma=+1(40 \%), \mu \sigma=-1(40 \%)$ и $-1<\mu \sigma<+1$. Такая обстановка говорит о пульсирующем режиме тектонических напряжений, о «встряхивании» горных пород, когда обстановка растяжения $(\mu \sigma=-1)$ попеременно (возможно, неоднократно) менялась на обстановку сжатия $(\mu \sigma=+1)$ при неизменной ориентировке осей сжатия и растяжения ЛСС, что способствовало подтоку гидротермальных растворов именно к таким участкам, так как горный хрусталь формировался на завершающем этапе герцинского тектогенеза после жильного этапа, в течение которого происходило массовое внедрение кварцевых жил [Karyakin, Smirnova, 1967].

Отметим, что в объемах горных пород восточнее рудоконтролирующего разлома на рис. 3 вид напряженного состояния был близок к трехосному, а сетка мелких разломов субширотного простирания, наряду с разломами СЗ простирания, аналогичными системе рудоконтролирующих разломов в юго-западной части месторождения, не оказалась благоприятной для образования гнезд горного хрусталя. По всей вероятности, изменение простирания рудоконтролирующего разлома в СВ части месторождения и его косое пересечение с мелкими разломами оказались неблагоприятными как для ВВНС, так и для образования гнезд с пьезосырьем. Для проверки этого предположения требуются дополнительные исследования.

Определения ЛСС III ранга проанализированы методом нахождения общих полей напряжений по данным о ЛСС в Пелингичейском, Омега-Шорском и ЗападноСаледском блоках.

Перераспределение и возмущение осей сжатия и растяжения внешнего поля в блоке с формированием ЛСС III ранга произошло из-за наличия неоднородностей внутри блоков: разрывов, складок и т.д. На рис. $4, a$,
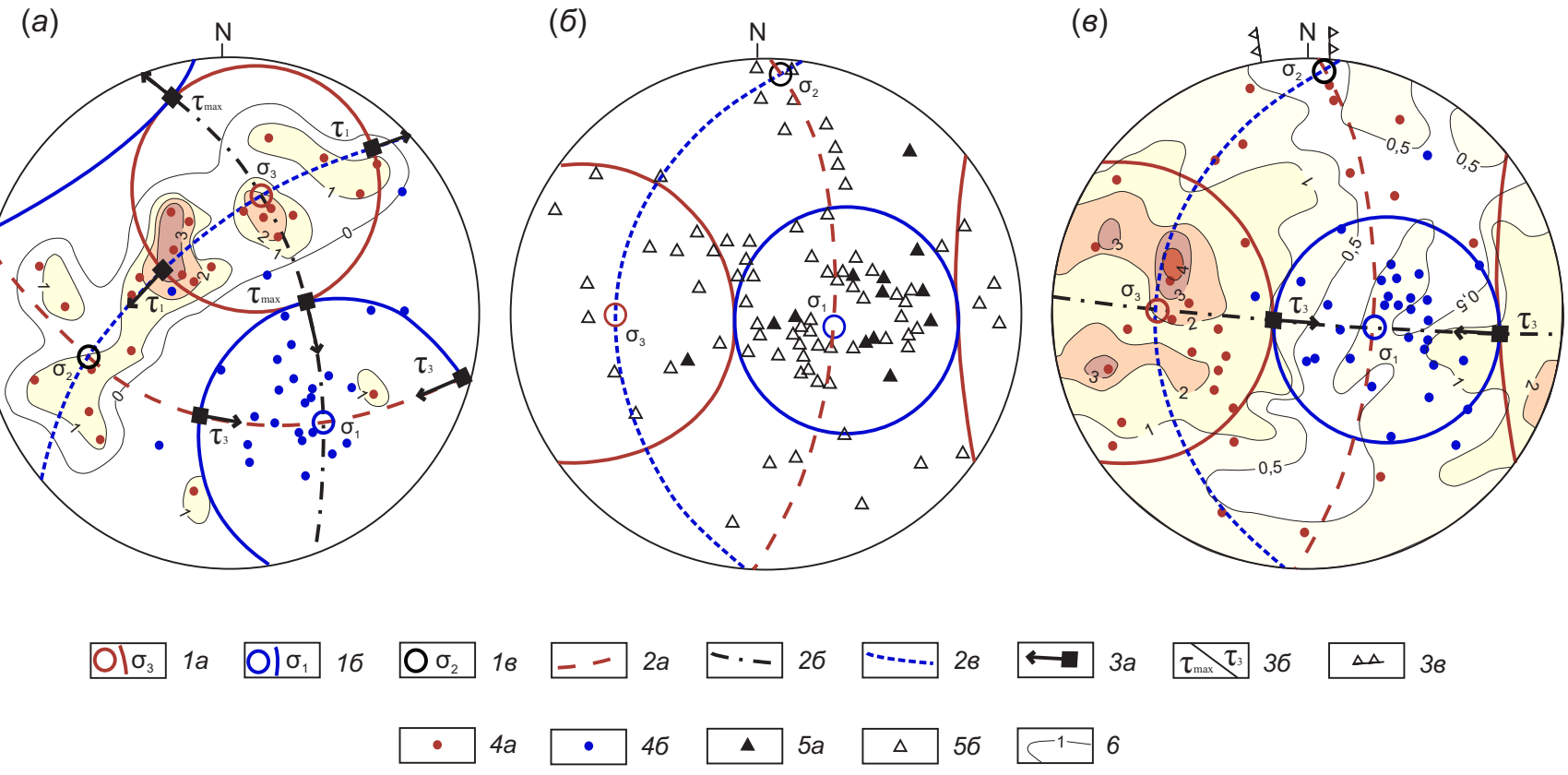

Рис. 4. Общее поле напряжений II ранга: (a) - Пелингичейского, (б), ( $($ ) - Омега-Шорского блока.

1 - оси главных нормальных напряжений общего поля напряжений и конуса: $a$ - сжатия, б - растяжения, в - ось промежуточных напряжений; 2 - плоскости действия: $a$ - оси сжатия, 6 - промежуточной оси, 8 - оси растяжения; 3 - полюсы плоскостей действия: $a$ - максимальных, $\sigma$ - прочих касательных напряжений, в - простирания плоскостей действия максимальных касательных напряжений взбросового типа; 4 - оси ЛСС: $a$ - сжатия, 6 - растяжения; 5 - полюсы кварцевых жил: $a$ - с гнездами и кристаллами горного хрусталя, 6 - без гнезд горного хрусталя; 6 - изолинии плотности осей сжатия ЛСС.

Fig. 4. General stress field (rank II). Blocks: (a) - Pelingichey, (б), ( $в$ ) - Omega-Shor.

1 - Axes of the main normal stresses of the general stress field and the cone: $a$-compression, $\sigma$ - tension, $\theta$ - intermediate stress axis; 2 - action planes: $a$ - compression, $\sigma$ - intermediate,,$\quad$ - tension; 3 - poles of action planes: $a$ - maximum, $\sigma$ - other tangential stresses, 8 - strike of maximum tangential stresses of the reverse fault type; 4 - LSS axis: $a$ - compression, $\sigma$ - tension; 5 - poles of quartz veins: $a$ - with quartz crystal nests and rock crystal, 6 - without quartz crystal nests s; 6 - isolines of compression LSS axis density. 
это требование соблюдается за исключением одного определения, которое приурочено к одному небольшому разрыву на месторождении; смещение по нему было вызвано ЛСС III ранга. По-видимому, это определение надо отнести к ЛСС IV ранга.

Концентрация осей растяжения в конусе растяжения общего поля напряжений Пелингичейского блока и поясное распределение осей сжатия ЛСС на стереограмме свидетельствуют о доминировании в Пелингичейском блоке обстановки растяжения. Обращает на себя внимание то, что максимум осей сжатия ЛСС на рис. 4 не совпадает с осью сжатия общего поля напряжений для блока. Это объясняется тем, что обсуждаемый максимум обусловлен частым совпадением оси сжатия локальных стресс-состояний с массовыми смещениями по плоскостям рассланцевания, отраженными на рис. 2, 6, которые характеризуются минимальным трением изза наличия на плоскостях рассланцевания слюдистых минералов [Sim, 2012]. Выбор более крутой ориентации оси сжатия обусловлен тем, что в пределах Кожимского поднятия доминируют ЛСС с крутой ориентировкой оси сжатия. Для Омега-Шорского блока общее поле напряжений также характеризуется высокой концентрацией осей растяжения ЛСС в конусе растяжения, при этом в этот конус попадают полюсы практически всех кварцевых жил с гнездами горного хрусталя, что показано на рис. 4, б, в.

\section{6. ЛИТЕРАTУPA/REFERENCES}

Angelier J., 1994. Fault slip analysis and paleostress reconstruction. In: P.L. Hancock (Ed.), Continental deformation. Pergamon Press, Oxford, p. 53-100.

Bott M.H.P., 1959. The mechanics of obique slip faulting. Geological Magazine 96 (2), 109-117. https://doi.org/10. $1017 /$ S0016756800059987.

Bukanov V.V., Burlakov E.V., Kozlov A.V., Pozhidaev N.A., 2012. Subpolar Urals: minerals of quartz crystal-bearing veins. Russian Mineralogical Almanac 17 (2), 26-31 (in Russian) [Буканов В.В., Бурлаков Е.В., Козлов А.В., Пожидаев Н.А. Приполярный Урал: минералы хрусталеносных жил // Минералогический альманах. 2012. Т. 17. Вып. 2. С. 26-31].

Gerasimov N.N., Krivoshein A.A., 2013. Quartz mining at the Zhelannoe deposit. Russian Mining Journal (9), 71-72 (in Russian) [Герасимов Н.Н., Кривошеин А.А. Добыча кварца на месторождении Желанное // Горный журнал. 2013. № 9. С. 71-72].

Gushchenko O.I., 1973. Analysis of the orientations of the slip on the fault plane and their tectonophysical interpretation during the reconstruction of palaeostresses. Doklady AN SSSR 210 (2), 331-334 (in Russian) [Гущенко О.И. Анализ ориентировок сколовых тектонических смещений и их тектонических смещений и их тектонофизическая интерпретация при реконструкции палеонапряжений // Доклады АН СССР. 1973. Т. 210. № 2. С. 331-334].

Gushchenko O.I., 1979. The method of kinematic analysis of destruction structures in reconstruction of tectonic stress fields. In: A.S. Grigoriev, D.N. Osokina (Eds), Fields of stress and strain in the lithosphere. Nauka, Moscow, p. 7-25
Таким образом, обстановка растяжения общего поля напряжения для крупного блока благоприятна для концентрации месторождений пьезосырья в этом блоке.

В Западно-Саледском безрудном блоке общее поле напряжений характеризуется трехосным напряженным состоянием без выраженной концентрации осей сжатия и растяжения ЛСС в одноименных конусах.

\section{4. ЗАКЛЮЧЕНИЕ}

В результате изучения тектонических напряжений в Приполярно-Уральской хрусталеносной провинции установлено следующее.

Гнезда горного хрусталя формируются в обстановке вариации вида напряженного состояния, характеризующегося сменой обстановки сжатия и обстановки растяжения. Этот особый вид напряженного состояния предлагается использовать в качестве тектонофизического критерия мест локализации гнезд горного хрусталя.

Общее поле напряжений блоков, насыщенных месторождениями и проявлениями пьезосырья, характеризуется общим для блоков коэффициентом Лоде Надаи, близким к обстановке растяжения.

\section{5. БЛАГОДАРНОСТИ}

Исследования выполнены при поддержке РФФИ в рамках научного проекта №17-05-01193а и по госзаданию ИФЗ РАН.

(in Russian) [Гущенко О.И. Метод кинематического анализа структур разрушения при реконструкции полей тектонических напряжений // Поля напряжений и деформаций в литосфере / Ред. А.С. Григорьев, Д.Н. Осокина. М.: Наука, 1979. С. 7-25].

Karyakin A.E., Smirnova V.A., 1967. Structures of Quartz Crystal-Bearing Fields. Nedra, Moscow. 240 p. (in Russian) [Карякин А.Е., Смирнова В.А. Структуры хрусталеносных полей. М.: Недра, 1967. 240 с.].

Lacombe 0., 2012. Do fault slip data inversions actually yield "paleostresses" that can be compared with contemporary stresses? A critical discussion. Comptes Rendus Geoscience 344 (3-4), 159-173. https://doi.org/10.1016/j. crte.2012.01.006.

Osokina D.N., 1987. On the hierarchical properties of the tectonic field of stresses and deformations in the Earth's crust. In: A.S. Grigoriev, D.N. Osokina (Eds), Fields of stresses and deformations in the Earth's crust. Nauka, Moscow, p. 136-151 (in Russian) [Осокина Д.Н. Об иерархических свойствах тектонического поля напряжений и деформаций в земной коре // Поля напряжений и деформаций в земной коре / Ред. А.С. Григорьев, Д.Н. Осокина. М.: Наука, 1987. С. 136-151].

Sim L.A., 2012. Some methodological aspects of tectonic stress reconstruction based on geological indicators. Comptes Rendus Geoscience 344 (3-4), 174-180. https:// doi.org/10.1016/j.crte.2011.11.003.

Sim L.A., Marinin A.V., 2015. Methods of field tectonophysics for identification of paleostresses. In: Modern tectonophysics. Methods and results. Materials of the Fourth 
Youth Tectonophysical Workshop. IPE RAS, Moscow. V. 2. P. 47-76 (in Russian) [Сим Л.А., Маринин А.В. Методы полевой тектонофизики по определению палеонапряжений // Современная тектонофизика. Методы и результаты: Материалы четвертой молодежной тектонофизической школы-семинара. М.: ИФЗ РАН, 2015. T. 2. C. 47-76].

Sim L.A., Yurchenko O.S., Sirotkina O.N., 2005. Tectonic stresses in the northern Urals. Geophysical Journal 27 (1), 110-120 (in Russian) [Сим Л.А., Юрченко О.С., Сироткина O.Н. Тектонические напряжения северных частей Урала // Геофизический журнал. 2005. Т. 27. № 1. C. 110-120].

Stephens T.L., Walker R.J., Healy D., Bubeck A., England R.W., 2018. Mechanical models to estimate the paleostress state from igneous intrusions. Solid Earth 9 (4), 847-858. https://doi.org/10.5194/se-9-847-2018.

Yamaji A., Sato K., 2011. Clustering of fracture orientations using a mixed Bing ham distribution and its application to paleostress analysis from dike or vein orientations. Journal of Structural Geology 33 (7), 1148-1157. https:// doi.org/10.1016/j.jsg.2011.05.006.

\section{LIDIA A. SIM}

Doctor of Geology and Mineralogy, Lead Researcher O.Yu. Schmidt Institute of Physics of the Earth of RAS 10 Bol'shaya Gruzinskaya St, Moscow D-242 123242, GSP-5, Russia e-mail: sim@ifz.ru

\section{ЛИДИЯ АНДРЕЕВНА СИМ}

докт. геол.-мин. наук, в.н.с. Институт физики Земли им. О.Ю. Шмидта РАН 123242, ГСП-5, Москва Д-242, ул. Большая Грузинская, 10 , Россия 